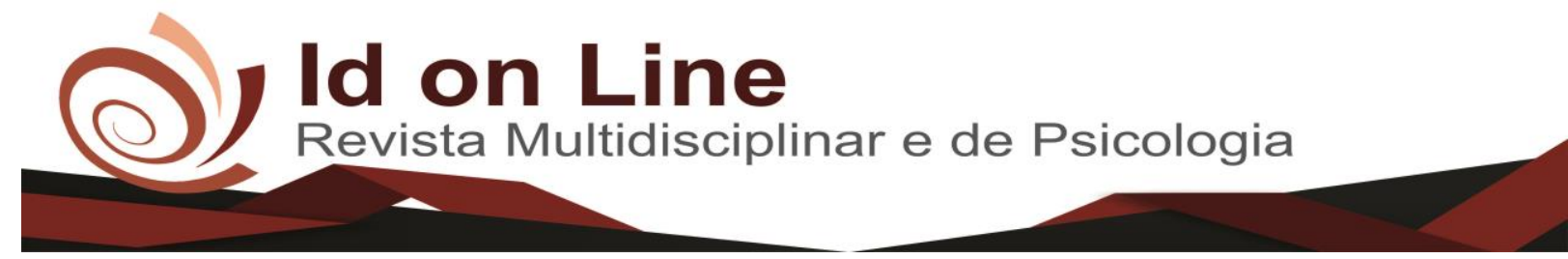

Artigo

\title{
O Construtivismo na Educação
}

Arlete Modesto Macedo Fernandes ${ }^{1}$; Gisanne de Oliveira Marinho ${ }^{2}$; Miriam Delmondes Batista ${ }^{3}$; Gislene Farias de Oliveira ${ }^{4}$

Resumo: Busca-se analisar a linha pedagógica do Construtivismo na educação, por meio de uma série de reflexões que envolvem desde seu conceito e críticas até a forma como o tema tem sido abordado e utilizado pelos professores das escolas públicas brasileiras. Outrossim, serão discutidas as práticas pedagógicas atualmente utilizadas, apontando uma possível postura que os professores devem assumir frente ao hodierno desafio da alfabetização da população. Para alcançar o referido objetivo, utilizará de pesquisa bibliográfica, baseadas principalmente em autores como SAVIANI (2004), OLIVEIRA (2008), POZO (1994), dentre outros que abordam o tema. Como resultado, a pesquisa revela que apesar das diversas críticas contra o Construtivismo, esse movimento trouxe muitas contribuições aos professores, principalmente porque com o estudo e aplicação de seus conceitos, a educação brasileira foi capaz de trilhar novos caminhos no sentido de superar o analfabetismo que tem acometido as crianças em idade escolar.

Palavras-chave: Alfabetização. Tradicionalismo. Construtivismo. Educador.

\section{Constructivism in Education}

Abstract:The aim is to analyze the pedagogical line of Constructivism in education through a series of reflections that involve from its concept and critics to the way the theme has been approached and used by the teachers of the Brazilian public schools. In addition, the pedagogical practices currently used will be discussed, pointing out a possible posture that teachers must take up against the current challenge of population literacy. In order to reach this goal, it will use bibliographical research, based mainly on authors such as SAVIANI (2004), OLIVEIRA (2008), POZO (1994), among others that approach the theme. As a result, the research reveals that in spite of several critiques against Constructivism, this movement brought many contributions to teachers, mainly because with the study and application of their concepts, Brazilian education was able to find new ways to overcome illiteracy that has affected children in school age.

Keywords: Literacy. Traditionalism. Constructivism. Education.

\footnotetext{
${ }^{1}$ Graduada em Pedagogia, especializada em psicopedagogia institucional. Mestranda em Educação pela Anne Syllivan University. Contato: arlete_modesto@hotmail.com.

${ }^{2}$ Mestranda em Justiça Administrativa na Universidade Federal Fluminente. Graduação em Direito pela Universidade Federal Fluminense concluída em 2016. Ordem dos Advogados do Brasil - Seccional do Rio de Janeiro. Contato: gihmarinho@ gmail.com;

${ }^{3}$ Mestranda em educação pela Anne Sullivan niversity; Contato: miriamdelmondes@ hotmail.com;

${ }^{4}$ Psicóloga, Doutora em Psicologia Social pela Universidade Federal da Paraíba - UFPB. Pós doutorado em Ciências da saúde pela Faculdade de Medicina do ABC - SP. E-mail: gislenefarias@gmail.com
} 


\section{Introdução}

A alfabetização consiste em um dos principais desafios enfrentados pela educação, isto se deve principalmente ao fato de quase todos os nossos modelos de alfabetização terem sido importados de outros países, que possuem contextos socioeconômicos muito divergentes do existente no Brasil.

O Brasil é detentor de vasta extensão territorial, que possibilita a existência de uma grande diversidade cultural, na qual se encontram, ainda, gritantes diferenças econômicas e sociais. Frente à esta problemática, a importação de modelos educacionais não tem sido exitosa, tendo em vista a dificuldade de se encontrar um protótipo que atenda a necessidade de todas as camadas sociais.

A educação tem papel fundamental na formação intelectual do indivíduo, visto que é a partir desta que se adquire boa parte dos valores, faz-se novas descobertas e alcançam-se objetivos, devendo, assim, ser cada vez mais difundida e considerada prioridade. No entanto, as hodiernas mudanças ocorridas em âmbito global, somadas somada às facilidades que a tecnologia tem possibilitado à vida cotidiana, parece posicionar a escola em um campo secundário.

$\mathrm{Na}$ falta de pesquisadores e autores nacionais que trabalhem no sentido de criar um padrão educacional exclusivo para o país, os gestores públicos têm encontrado na importação de modelos e ideologias educacionais a solução para o problema. E, dentre tantos modelos adotados pelo Brasil, está o Construtivismo, "método de alfabetização" inspirado nas ideias do suíço Jean Piaget (1896-1980).

No cenário educacional vigente, é perceptível que muitos professores ainda utilizam o tradicionalismo pedagógico para guiar suas aulas, sendo este inexpressivo e ineficaz em relação a qualidade do ensino-aprendizagem, bem como quanto a educação especial. Esta falta de iniciativa de atualização profissional por parte de alguns docentes é vista como forma de “comodismo profissional”, em que o professor se abstém de procurar métodos inovadores para ministrar suas aulas, permanecendo preso ao antigo modelo tradicional de ensinar.

Neste diapasão, o Construtivismo é apontado como uma possível solução de acabar com o tradicionalismo pedagógico que ainda existe em algumas escolas do país, no qual os alunos participam e constroem sua própria aprendizagem, a partir de seus próprios 
conhecimentos e de sua interação com a realidade e com os colegas de classe. Assim, com seus conceitos e críticas, o Construtivismo tem chamado atenção por propor um processo inovador com relação a alfabetização, visto que transfere o foco do processo de aprendizagem do professor para o aluno.

O presente estudo é de natureza bibliográfica, baseando-se tão somente em uma discussão acerca de pontos de vistas de diversos autores sobre o tema, com fulcro de, ao final, demonstrar que este parece ser um método útil e eficaz no combate do analfabetismo.

\section{O Processo Ensino Aprendizagem}

Atualmente, é cada vez maior o quantitativo de educandos com lacunas de aprendizagem. Isto decorre, principalmente, dos avanços tecnológicos, que desenvolveu tablets, smartphones, notebooks, dentro outros aplicativos que desviam facilmente a atenção do aluno do aprendizado. Sendo assim, a utilização do modelo convencional de ensino não tem demonstrando ser a melhor alternativa.

Assim, cabe uma reflexão: de quem seria a culpa? Do Estado com sua política educacional tradicional e ainda não abarcada pelo novo modelo mundial de educação? Gestores um tanto descompromissados com uma avaliação institucional mais abrangente? Escolas mal equipadas? Materiais didáticos fora de contexto? Pais que não possuem uma participação mais efetiva para cobrar um melhor posicionamento da escola quanto a tais questões?

Aprendizagem trata-se de processo pautado principalmente na comparação de diferentes perspectivas, bem como por meio da análise de diversas teorias de conhecimento. Sendo assim, dá-se por meio de estudos, experiências, raciocínios e observações, que são desenvolvidos durante o processo, e que, ao final, possibilitam que o indivíduo adquira novas competências, habilidades, conhecimentos, comportamentos e valores, que podem, inclusive, ser modificados no decorrer da construção do aprendizado.

Nesse sentido, urge mencionar que o aprendizado do indivíduo ocorre de forma mais eficaz quando a educação se encontra correlacionada com seu desenvolvimento pessoal. Dessa forma, o método educacional utilizado deve estar em conformidade com a realidade do 
educando, isto porque, uma aprendizagem escolar desenvolvida de forma que o aluno tenha dificuldade em assimilar o que está sendo repassado, está fadada ao fracasso.

Para Fernández (1998), de uma breve análise do estado atual do processo de ensino e aprendizagem, é possível identificar um movimento de ideias advindo de diferentes correntes teóricas envolvendo o binômio ensino-aprendizagem. Dentre essas, destaca-se a Teoria Construtivista de Piaget, sendo está fundamentada em buscar desenvolver a curiosidade do estudante, que é estimulado a encontrar respostas a partir dos seus próprios conhecimentos, bem como por intermédio da interação com os demais alunos.

$\mathrm{Na}$ atualidade, temos um sistema de ensino pautado basicamente na memorização de assuntos, em que não há a devida preocupação com o desenvolvimento das habilidades de reflexão crítica acerca dos conhecimentos que são lecionados. Dessa forma, é notório que o método utilizado não está funcionando, carecendo, assim, de reforma.

\section{As Consequências do Tradicionalismo}

Juntamente com o aparecimento de novos pensadores e doutrinadores no campo da educação, surgiram novas ideias, teorias, novos métodos de trabalho dentro da sala de aula; todos apontando no sentindo de quebrar paradigmas deixados pela escola do tradicionalismo pedagógico.

Muitas mudanças estavam rapidamente acontecendo e o modelo de ensino brasileiro, preso ao fracassado método Tradicionalista, não estava acompanhando o mesmo ritmo. $\mathrm{O}$ principal problema consiste nos docentes que não abrem mão da utilização do Tradicionalismo, e continuam usando a avaliação de ensino para aprovar ou reprovar alunos, bem como se negavam a abrir mão do autocontrole de suas turmas, apesar das punições mais severas terem sido proibidas (PISTRAK, 2005).

A política também configura um dos grandes problemas para a educação, isto porque é recorrente o início de um sistema, que logo é substituído por renovada proposta. Como resultado, ao longo dos anos a educação apenas enfrenta muita burocracia e pouca ação dentro do sistema educacional.

Ademais, vê-se a valorização de diversas categorias profissionais, mas com relação aos professores, nenhuma mudança significativa foi notada. $\mathrm{O}$ professor continua submisso a 
categorias políticas, o que impedia que muitos docentes participassem de manifestações em prol de seus direitos por medo de possíveis retaliações, tendo em vista que muitos perderam seus empregos para servir de exemplo para os demais. Inclusive, até hoje esse medo impera. (RAMOS, 2007).

Em meio a tanta luta por mudanças, uma coisa era certa: o sistema escolar clamava por mudanças. Era preciso adaptá-lo ao meio em que estava inserido, a sociedade já exigia uma pessoa mais reflexiva, crítica, capaz de transformar situações em soluções.

Nesse diapasão, em 1988, o governo editou nova constituição, baseada nos princípios de igualdade e justiça, trazendo, em seu capítulo destinado a educação, cultura e esporte; tanto novidades quanto exigências para a educação:

A educação, direito de todos e dever do Estado e da Família, será promovida e incentivada com a colaboração da sociedade, visando ao pleno desenvolvimento da pessoa, seu preparo para o exercício da cidadania e sua qualificação para o trabalho.”(BRASIL, 1998, p.32)

Nota-se a importância que foi conferida à educação e, com isso, os sonhos de muitos setores do país, metas que antes apenas eram planejadas no papel, foram reavivadas.

Infelizmente até hoje o país não teve condições de implementar todas as metas traçadas, em razão da corrupção inerente ao próprio sistema público. Alguns tentam culpar essa falta recursos público, mas, na verdade, a inexecução das políticas públicas está intimamente correlacionada a questões político-administrativas, que desvia indevidamente verbas da educação para outro setor, ou até mesmo para os próprios políticos.

A função social da escola, segundo a Constituição de 1988, consiste na promoção do desenvolvimento do indivíduo, preparando-o para o exercício da cidadania e sua qualificação profissional, com o auxílio da família e da sociedade. Nesse sentido, este trabalho propõe que a escola, família e sociedade, trabalhem em conjunto para fins possibilitar que o aluno se torne um agente transformador da sociedade, tendo em vista que as crianças são consideradas o futuro da nação.

Nessa proposta, a escola atuará como formadora da base teórica, dos conceitos, das normas e das fórmulas que influenciarão no aprendizado educando; a família será responsável pela construção da base moral e ética da criança; e a sociedade, será encarregada de possibilitar o envolvimento do jovem no âmbito social, para que este exerça sua cidadania de forma a contribuir com o progresso da Nação (RAMOS, 2007). 
A Constituição Federal de 1988, trouxe novos conceitos para o campo educacional. Dentre eles, cabe ressaltar o da gratuidade, por meio do qual a educação para a ser direito fundamental, de acesso à todo e qualquer cidadão, sem preconceitos nem discriminações. Da mesma forma, dispôs no sentido da defesa da liberdade de aprender, ensinar, pesquisar e divulgar o pensamento, a arte e o saber.

Vale ressaltar que a educação pública é gratuita foi conquista de movimentos sociais do século XX, mesma época em que também houve a expansão de escolas visando o processo de universalização do Ensino Fundamental, contudo, sem a devida preocupação com a qualidade do ensino.

Segundo Pistrak (2005), com a edição da Carta Magna de 1988, surgiu a "utopia da educação", na qual no papel haviam normas e procedimentos que descreviam um sistema educacional de sucesso, que, no entanto, nunca iria se efetivas (PISTRAK, 2005) em razão do sistema público desvirtuado na qual esta encontra-se inserida.

Apesar de estar diante de uma nova metodologia, os profissionais da educação ainda resistiam as mudanças, insistindo em utilizar técnicas do antigo regime como avaliações de ensino para medir conhecimento, priorização da quantidade ao invés da qualidade etc. Estes profissionais estão cada vez mais pressionados a mudar sua forma de atuação, principalmente em razão da globalização, que além de criar um novo mundo de trabalho, também passou a exigir da escola a formação um novo tipo trabalhador, que seja polivalente, flexível, motivado, articulado, criativo, que possua facilidade em desenvolver trabalhos em equipe.

Ao final, não houve a valorização do profissional da educação, no entanto, cada vez mais nota-se o aumento das exigências de qualificação destes. E o professor, apesar de já possuir um grau de estudo relevante, começou a entender que com processo de mudança que estava acontecendo na educação, seu próprio conhecimento estava ficando ultrapassado. E, de repente, o professor sai do centro das atenções para dar lugar ao aluno (SAVIANI, 2004).

\section{Conceituando Construtivismo}

Há algum tempo atrás, a alfabetização de crianças envolvia meramente a soletração de palavras soltas, mesmo que sem sentido, ensinar a escrever seu nome, ajudar na realização de alguns exercícios e a básica de leitura de textos. Ou seja, diversas práticas pedagógicas 
desprovidas de criatividade e criticidade, colocando o educador na posição de mero reprodutor de informações soltas e aleatórias. Embora essa prática ainda perdure em parte significativa das escolas, as contribuições do movimento Construtivista têm trazido significativas mudanças para as escolas brasileiras. A doutrinadora Pozo (1994, p. 24) corrobora com esse entendimento:

O construtivismo propõe que o aluno participe ativamente do próprio aprendizado, mediante a experimentação, a pesquisa em grupo, o estímulo a dúvida e o desenvolvimento do raciocínio, entre outros procedimentos. A partir de sua ação, vai estabelecendo as propriedades dos objetos e construindo as características do mundo. As escolas que usam o método construtivista têm características de estrutura diferentes das escolas que usam outros métodos. (POZO, 1994, p. 24)

Assim, aplicando as ideias do Construtivismo, foi possível verificar que mudanças na postura do educador dentro da escola, tem resultado em melhoras satisfatórias no ensino. Com a implantação das propostas do modelo, as aulas se tornaram vivas e significativas, o aluno passou a interagir, e o professor também ganhou mais espaço para desenvolver sua criatividade, para fins de tornar as aulas mais dinâmicas e produtivas. Houve, então, uma aparente transformação no ambiente escolar que possibilitou a canalização de forças no sentido de atingir as metas e objetivos da educação.

\begin{abstract}
Construtivismo é uma das correntes teóricas empenhadas em explicar como a inteligência humana se desenvolve partindo do princípio de que o desenvolvimento da inteligência é determinado pelas ações mútuas entre o indivíduo e o meio. Esta concepção do conhecimento e da aprendizagem que derivam, principalmente, das teorias da epistemologia genética de Jean Piaget parte da ideia deque o homem não nasce inteligente, mas também não é passivo sob a influência do meio, isto é, ele responde aos estímulos externos agindo sobre eles para construir e organizar o seu próprio conhecimento, de forma cada vez mais elaborada. Azenha, (1997) apud (POZO, 1994, p.18)
\end{abstract}

Dessa forma, é patente que o Construtivismo se trata de movimento importante na atualidade, isto porque, a partir dele é possível mapear o funcionamento e apreensão da aprendizagem, por meio do qual é possível demonstrar que todo indivíduo é dotado de inteligência, sendo apenas necessário que estímulos a desenvolvam e ampliem, sendo esses estímulos a porta de entrada para efetivação dessas aprendizagens.

O modelo Construtivista tem sido adotado por diversas instituições, o que vem possibilitando o uso de um ensino diferenciado e mais dinâmico, na medida em que o professor é capaz de utilizar na sala de aula um novo método pedagógico, que favorece, principalmente, o desenvolvimento das potencialidades das crianças. 
Dessa forma, este método tem sido fundamentalmente importante, visto que, por meio de seus pressupostos de compreensão dos caminhos do desenvolvimento da inteligência, é possível identificar diferentes contribuições para o processo de alfabetização. A principal delas está correlacionada com a compreensão de que o aluno deve ter liberdade para aprender das mais diversas formas, seja em grupo ou individualmente, sempre respeitando seus limites e necessidades de aprendizagem de cada um.

\section{Algumas Críticas Proferidas ao Construtivismo}

Caso fosse realizada uma breve pesquisa a respeito de qual método de alfabetização os educadores utilizam nas escolas brasileiras, parte significativa responderia que utiliza o método Construtivista, isto porque é um assunto que se encontra em evidência no país, contudo, ainda carece de um estudo mais aprofundado acerca do tema. Na verdade, o que existe no Brasil são ideias soltas e desorganizadas a respeito de um movimento educacional que teve início da Europa, que, em diversas situações, trazem conceitos contrários aqueles inerentes a Escola Construtivista.

\footnotetext{
É muito difícil definir o que seja "construtivismo". No Brasil não existem propostas teóricas originais que permitiriam caracterizar algum autor nacional como "construtivista". O que existe são pessoas que se auto intitulam construtivistas, seja divulgando ideias e instrumentos desse movimento, seja considerando-se um praticante dessas ideias. Muitas autores são citados em conexão com as ideias construtivistas. Os mais frequentemente citadas são Piaget e Vygotsky, que compartilham entre si algumas ideias e divergem frontalmente em outras. Mais comumente são pouco lidos e muito incompreendidos. (OLIVEIRA, 2008, p. 429).
}

$\mathrm{Na}$ falta de um modelo nacional de educação eficaz que supra as necessidades e dificuldades dos professores, o Construtivismo tem ganhado espaço, isto porque além de introduzir uma nova forma de lecionar para ser aplicada pelos professores, também comunga com as ideias mercadológicas e reproduz os interesses da classe opressora da sociedade.

Classificar o construtivismo um método de ensino, pode significar um dos maiores equívocos cometidos no processo de alfabetização, sendo esta uma das mais fortes críticas acerca de sua implantação nas escolas brasileiras. Ademais, critica-se fortemente o termo que tem sido utilizado para se referir ao uso do modelo Construtivista, qual seja, "construção do conhecimento", uma vez que esta expressão resta desprovida de validade filosófica e utilidade 
científica no domínio da psicologia cognitiva (OLIVEIRA, 2008, p.432). A esse respeito o autor comenta que:

É correto afirmar que todo conhecimento é elaborado individualmente, que cada pessoa elabora e estrutura a seu modo os estímulos que recebe do meio ambiente. Mais isso é uma verdade que se aplica a todo tipo de experiência -dançar, executar música, ver o pôr-do-sol, aprender física. Cada um de nós vivencia e interpreta diferentemente as coisas. O que acontece em nosso cérebro, nesse sentido é um fenômeno único, como cada pessoa "constrói" a sua apendicite, o seu câncer ou o seu estado de vigor atlético. [...] Mas o fato dessas coisas ocorrerem com as pessoas, não significa que elas se constituam necessariamente num fenômeno individual no sentido idiossincrático, no sentido de ser exclusivo. Apesar das grandes controvérsias existentes em torno da questão da objetividade do conhecimento, dois pontos parecem convergir. O primeiro é que o processo de construção do saber é um empreendimento coletivo, e não individual. Isso se aplica ao saber filosófico e ao científico, aos artefatos da cultura, ao saber do senso comum. O segundo é que o mundo "externo" -físico, social, natural, humano- não é passivo, e não pode ser construído de qualquer maneira. (OLIVEIRA, 2008, p. 433).

Resta claro que as críticas apresentadas ganham validade com base no fato de que a criança não constrói seu conhecimento sozinha, sendo necessária a interferência do mundo “externo", por meio de interações sociais, culturais, críticas e com sua realidade social, mediada pela intervenção direta do professor.

Ao longo do estudo percebemos que alguns conceitos perdem validade, como é o caso da frase "ninguém ensina ninguém, o aluno constrói o seu próprio conhecimento" (OLIVEIRA, 2008). Esta célebre frase não apresenta corporeidade, pois, na prática, sua efetivação não é passível de concretização, já que para construir o conhecimento a criança precisa de interação com o meio externo, conforme já mencionado. Sobre o assunto trazemos passagem da teoria do doutrinador Vygotsky (1978):

[...] no conceito de zona de desenvolvimento proximal (ZDP). Ele observou que as crianças aumentam muito seu desenvolvimento quando ajudada por adultos. A ZDP consiste na diferença entre o que uma criança pode fazer sozinha e o tanto de ajuda de que necessita. A função dos adultos é identificar o nível de ajuda necessária e apoiar a criança, ou seja, servir de andaime para que ela progrida. Seria difícil inferir dessas informações que "ninguém ensina nada a ninguém "e que a criança vai "construir" seu próprio desenvolvimento ou conhecimento". Apud. (OLIVEIRA, 2008, p. 436)

Desse modo, é incontroverso que o aprendizado da criança está diretamente correlacionado com interações externas, principalmente realizadas com os adultos, bem como que o conhecimento produzido é fruto de outras experiências já vivenciadas pelas sociedades 
nas quais os indivíduos estão inseridos, cada uma com suas particularidades e contextos sociais próprios.

\section{O Cotidiano Pedagógico e o Construtivismo}

A afirmação de que "o mestre só é mestre porque tem conhecimento e, por tê-los, pode ajudar outrem a aprender" (OLIVEIRA, 2008), é perfeitamente cabível na prática pedagógica, na qual o educador deve buscar, qualificar-se profissionalmente para compreender de modo substancial os desafios de alfabetizar.

Nesse diapasão, considera-se impossível que o professor obtenha êxito na missão de educar, caso não compreenda previamente as formas de alfabetização. Esta, por sua vez, pressupõe a existência de métodos próprios, inerentes ao fazer pedagógico, devendo o professor conhecer tanto a técnica, quanto os seus possíveis desdobramentos.

Segundo consta nos Parâmetros Curriculares Nacionais, estabelecidos pelo MEC, “a alfabetização, considerada em seu sentido restrito de aquisição da escrita alfabética, ocorre dentro de um processo mais amplo de aprendizagem da Língua Portuguesa" (PCN, 1998). Esse processo ganha sentido quando o professor trabalha as leituras de modo interativo, dando vida ao texto, saindo assim da mera decodificação de letras e palavras soltas, dando a escrita alfabética a possibilidade de produzir e compreender os textos em estudo.

Nesse sentido, a compreensão sobre os métodos de alfabetização demonstra ser de suma importância, pois ultrapassam a mera mecanização de atos constantemente reproduzidos no interior da escola. Kamer (2010, p. 98) descreve a alfabetização da seguinte forma:

\footnotetext{
[...] entendo que alfabetizar-se é conhecer o mundo, comunicando-se e expressandose. Isso significa que uma criança começa a ler quando descobre que o mundo é feito de coisas que pode pegar, cheirar, apertar, morder etc., e que pode ser imitado, dramatizado, expresso na música, na dança, no desenho, na fotografia, na colagem, na palavra falada, na palavra escrita. [...]. Alfabetizar não se restringe à decodificação e aplicação de rituais repetitivos de escrita, leitura e cálculo. [...]. (KAMER, 2010, p. 98).
}

Essa forma mais ampla de compreensão alfabetização, orienta o educador no sentido de entender seus desafios e buscar solucioná-los de modo coletivo, envolvendo todos os segmentos da escola - pais, professores, funcionários e comunidade - aproveitando a diversidade de 
conhecimentos e valores trazidos pelos alunos para alfabetizar de forma mais interativa e atrativa por meio de uma troca de conhecimento direta entre os educandos, sempre com a preocupação principal de que os alunos saiam da escola de fato alfabetizados na idade certa, até o terceiro ano do Ensino Fundamental.

À partir dessa nova percepção da realidade educacional, que o professor deve procurar prever e sanar os possíveis problemas que poderão surgir no decorrer do ano letivo. Em regra, o educador elabora uma agenda de atividade que deverá ser rigorosamente seguida, e, no decorrer das atividades, observando as particularidades de cada aluno, ele aponta a necessidade de aulas de reforço escolar, orienta os pais acerca do modo como devem ser realizados os acompanhamentos das atividades de casa, ressalta a importância do aluno não perder a nenhum dia letivo, etc.

Assim, é comum adentrar em uma escola e se deparar com alunos realizando atividades diferenciadas no pátio da escola, na quadra, embaixo de uma árvore, nas residências dos próprios familiares, e outros ambientes que possuem a capacidade de serem utilizados como ambiente de alfabetização. É perceptível que este tipo de didática ajuda os educando a superar possíveis problemas e limitações, causando, ainda, uma sensação de bem-estar na criança, que passa a gostar do ambiente educacional, pois passa a ver aquele lugar como um ambiente de descobertas e de aprendizagens.

A sala de aula se transforma num verdadeiro laboratório, ambiente de construção do saber, em que todas as paredes são aproveitadas para expor a produção textual e artística dos educandos, como forma de incentivá-los e parabeniza-los. Assim, temos uma sala de aula incomum, em que os alunos são divididos em pequenos grupos para facilitar a interação entre os educandos, bem como para tornar mais o direcionamento das atividades pelo professor.

Essa relação estabelecida entre o professor e o aluno acontece, como explica Paulo Freire (1996) de modo horizontal, na qual também confere ao aluno o poder de discutir com criticidade o assunto trabalhado.

Durante o processo de alfabetização, o educador procurar trabalhar conteúdos relacionados ao cotidiano das crianças. Nessa perspectiva, o educador traz para sala de aula situações capazes de desenvolver em seus alunos uma visão crítica do mundo que o cerca. Conforme orientação da Secretaria da Educação Fundamental: 
[...] Para desenvolver sua prática os professores precisam também desenvolver-se como professionais e como sujeitos críticos na realidade em que estão, isto é, precisam poder situar-se como educadores e como cidadãos, e, como tais, participantes do processo de construção da cidadania, de reconhecimento de seus direitos e deveres, de valorização profissional. (BRASIL, 1998, p. 31).

Por fim, percebemos nessas atitudes a presença do método Construtivista, e, com essa postura, o educador, além tornar a alfabetização uma atividade dinâmica, interessante e prazerosa; consegue questionar os mais diversos problemas recorrentes na sociedade, envolvendo as crianças e suas famílias, bem como construir em conjunto uma possível solução dos mesmos. No entanto, mesmo sendo importante estimular o senso crítico e questionionador dos educandos, deve-se evitar exageros que podem ser nocivos ao processo.

\section{Considerações Finais}

As escolas públicas brasileiras, em especial as responsáveis pela alfabetização de crianças, carecem de experiências profissionais bem-sucedidas, bem fundamentadas e, acima de tudo, verdadeiras. No entanto, é preciso retratar a realidade das salas de aulas, com seus defeitos e qualidades, para que seja possível identificar os principais problemas que a acometem o sistema atual, para fins de solucioná-los com a devida competência e responsabilidade.

Hodiernamente, é inadmissível que uma criança conclua o ensino fundamental sem a devida alfabetização. E, como peça principal desse processo de aprendizagem, temos o professor, que carrega a importante missão de tentar garantir que todos os educandos sejam alfabetizados e concluam o terceiro ano do ensino fundamental com a idade certa.

Apesar de ser um longo percurso a ser percorrido, é evidente que a educação brasileira trilhou novos caminhos e objetivos após a divulgação das ideias do Construtivismo. Sendo assim, apesar das críticas existentes ao método, este movimento traz, em sua essencialidade, inúmeras contribuições que poderão auxiliar o educador no desenvolver de sua atividade, com o escopo de superar o analfabetismo atualmente presente e crescente no país. 


\section{Referências}

BRASIL; Secretaria de Educação Fundamental. Parâmetros Curriculares Nacionais: terceiros e quarto ciclos: apresentação dos temas transversais. Brasília: MEC/SEF, 1998.

FREIRE, Paulo. Pedagogia da autonomia: saberes necessários à prática educativa. São Paulo: Paz e $1996 . \quad$ Terra, Disponível em:<:http://pt.wikipedia.org/wiki/Socioconstrutivismo>.Acessada em 01 de agosto de 2016

KRAMER, Sonia. Alfabetização leitura e escrita: formação de professores em curso. São Paulo: Ática, 2010.

OLIVEIRA, Joao Batista Araújo e. Programa Alfa e Beta: ABC do Alfabetizador: 7 ed. Rio de Janeiro, 2008.

PÉREZ GÓMEZ, A. I. As Funções Sociais da Escola: da reprodução à reconstrução crítica do conhecimento e da experiência. In GIMENO SACRISTÁN, J.; PÉREZ GÓMEZ, A. I. Compreender e Transformar o Ensino. 4 ed. Porto Alegre: ArtMed, 1998.

PISTRAK. Fundamentos da escola do trabalho. Tradução Daniel Aarão Reis Filho. $4^{\mathrm{a}}$. Ed. São Paulo: Editora Expressão Popular Ltda., 2005.

POZO, Juan Ignacio. Teorias cognitivas del aprendizaje. 3 ed. Madrid: Morata, 1994.

RAMOS, Jeannette F. P. Ramos, MAIA, Gilberto B., CHAVES, Sâmara Almeida. Trabalho docente alienado. 2007.

ROMANELLI, Otaiza de Oliveira. História da educação no Brasil. 24 ed. Petrópolis: Vozes, 2000.

SAVIANI, Dermeval. Educação: do senso comum à consciência filosófica. 15a . Ed. Campinas, SP: Autores Associados, 2004.

VYGOTSKI, L. S. Teoria e método em Psicologia. São Paulo: Martins Fontes, 1996.

Como citar este artigo (Formato ABNT):

FERNANDES, Arlete M.M.; MARINHO, Gisanne de O.; BATISTA, Miriam D.; OLIVEIRA, Gislene F. O Construtivismo na Educação. Id on Line Rev.Mult. Psic., 2018, vol.12, n.40, p.138-150. ISSN: 1981-1179.

Recebido: $16 / 02 / 2018$

Aceito 20/02/2018 